\title{
APLICATIVOS DE APOIO A EXPERIÊNCIA TURÍSTICA: FERRAMENTAS PARA A ANÁLISE DE SIMILARES
}

\section{TOURISTIC EXPERIENCE SUPPORT APPS: TOOLS FOR SIMILAR ANALYSIS}

\author{
Mariana Soares Popper ${ }^{1}$, Designer \\ Berenice Santos Gonçalves², Dra. \\ (1) Universidade Federal de Santa Catarina \\ e-mail: poppermariana@gmail.com \\ (2) Universidade Federal de Santa Catarina \\ e-mail: bereni.gon@gmail.com
}

Análise de similares, Interface, Mobile

\begin{abstract}
Os smartphones criam oportunidades de negócios e no setor turístico, o conhecimento sobre experiência do usuário melhora a experiência turística. A partir deste contexto, este artigo teve como objetivo analisar a interface de aplicativos de apoio a experiência turística. Foram caracterizadas e aplicadas duas ferramentas, uma objetiva e a outra descritiva, para a análise da interface de aplicativos similares.
\end{abstract}

\section{Similar analysis, Interface, Mobile}

The smartphones create business opportunities and at the touristic sector, the knowledge about user experience improves the touristic experience. From this context, this article aims to analyse the interface of apps that support the touristic experience. Two tools were characterised and applied, one objective and the other descriptive, to analyse the interface of similar apps.

\section{Introdução}

Os smartphones são uma tecnologia cuja relevância avança constantemente por seu crescimento de uso e difusão do desenvolvimento de programas dedicados a eles. Este fato se revela verdadeiro, pois no ano de 2015, cerca de 72, 4 milhões de brasileiros acessaram a internet através de seus smartphones [NIELSEN COMPANY, 2015]. Os benefícios que essa tecnologia proporciona, abrangem diversas áreas, por tornar possíveis não apenas a criação de novos serviços, mas também agregar valor aos já existentes.

Assim como a experiência do usuário é formada a partir de sensações e conclusões do usuário [ROYO, 2008], a experiência turística se constrói a partir das vivências de uma pessoa fora de seu contexto habitual, seu cotidiano [URRY, 2011]. Desse modo, os conhecimentos adquiridos sobre 


\section{$16^{\circ}$ \\ ERGODESIGN USIHC CINAHPA}

experiência do usuário contribuem de maneira significativa para a melhoria da experiência turística através das interfaces gráficas.

Constituídas por elementos compreendidos como instrumentos metafóricos de uma realidade com a qual o usuário está familiarizado, as interfaces são parte da realidade tal qual qualquer objeto fora de um sistema [BONSIEPE, 2015]. Desta forma um aplicativo de smartphone, vem como forma de apoio a experiência turística, pois reúne elementos que o usuário está familiarizado para a solução de problemas em um contexto desconhecido.

Dentre os momentos onde a tecnologia surge como apoio em contexto de viagem, identificou-se a necessidade de centralização de informações sobre comida de rua. A partir desta constatação, iniciou-se o desenvolvimento de um aplicativo para suprir essa demanda. No início da metodologia foi feita a análise de similares e para isso, foram utilizadas duas ferramentas, uma objetiva $(\mathrm{MATcH})$ e uma subjetiva (Visual Usability), cujos resultados serão apresentados a seguir.

\section{Experiência e usabilidade}

A busca por experiências prazerosas e distintas do que se vive no cotidiano é o guia para o desenvolvimento e evolução da experiência turística. Este consumo de bens que podem ser vistos como desnecessários, consiste em lançar o olhar sobre cenários, paisagens e outros elementos que são incomuns a vivência do turista [URRY, 2001]. Para que esta experiência ocorra, é necessária uma grande quantidade de troca de informações, como para a reserva de hotéis e a definição de roteiros [BETTONI, 2009 apud SANTOS,

SANTOS, 2014]. Por este motivo, o smartphone aparece como um dispositivo de grande valor, já que através do seu uso são acessadas informações já conhecidas ou resolvidos problemas inesperados [SANTOS, SANTOS, 2014].

Neste contexto apresenta-se o design de interação, cujo objetivo através da união da usabilidade e do design visual é fazer com que o usuário tenha uma experiência bem-sucedida. As sensações, valores e conclusões que ele obtém ao fazer o uso de um determinado equipamento ou interface, são os $16^{\circ}$ Ergodesign - Congresso Internacional de Ergonomia e Usabilidade de Interfaces Humano Tecnológica: Produto, Informações Ambientes Construídos e Transporte

$16^{\circ}$ USIHC - Congresso Internacional de Ergonomia e Usabilidade de Interfaces Humano Computador

CINAHPA | 2017 - Congresso Internacional de Ambientes Hipermídia para Aprendizagem.

elementos que formam a experiência do usuário. Frutos das experiências funcionais, ela também não deixa de ser reflexo da experiência estética, assim como dos objetivos do usuário e das variáveis culturais [ROYO, 2008].

Definida pela Organização Internacional para a Padronização (ISO) como a efetividade, eficiência e satisfação que um produto permite atender aos objetivos específicos de determinados usuários em um contexto de uso definido, a usabilidade [ROYO, 2008] é um dos fatores determinantes para que o sucesso seja atingido em quando se projeta a experiência do usuário. Como a partir da criação e sincronização de elementos na interface é possível influenciar as percepções e o comportamento dos usuários [UNGER, 2009], faz se necessário analisar as soluções propostas por similares como parte do processo de desenvolvimento de um aplicativo.

\section{Ferramentas de análise}

Para o desenvolvimento das análises, foram combinadas duas ferramentas, a MATch, objetiva e baseada nas heurísticas de Nielsen [1995] e os critérios de usabilidade visual propostos por Tania Schlatter e Deborah Levinson [2013].

\subsection{MATcH}

A análise de similares foi iniciada com a ferramenta MATcH, um checklist de usabilidade baseado nas 10 heurísticas de Nielsen [1995], que foi desenvolvido pelo GQS/INCoD/UFSC. A partir da análise do trabalho de Nielsen, conseguiu-se uma estrutura com 48 questões, que possuem 3 respostas possíveis: sim (se o aplicativo está de acordo com a questão), não (se o aplicativo não está de acordo com a questão) e não se aplica (se a questão não diz respeito ao aplicativo) [FEIJÓ, GONÇALVES, GOMEZ, 2013]. A ferramenta foi desenvolvida com o intuito de minimizar problemas de usabilidade de sistemas em dispositivos touchscreen, e está disponível em http://www.gqs.ufsc.br/match-q/ (SALAZAR apud FEIJÓ, GONÇALVES, GOMEZ, 2013).

Realização:




\section{$16^{\circ}$ \\ ERGODESIGN USIHC CINAHPA}

\subsection{Usabilidade Visual}

Os critérios definidos no livro Visual Usability, por Tania Schlatter e Deborah Levinson [2013] foram adotados para a segunda parte da análise. As autoras consideram os seguintes meta princípios de usabilidade: consistência, a hierarquia e a personalidade. Os meios pelos quais estes princípios são construídos são os elementos de design, que atuam como ferramentas de usabilidade.

\subsubsection{Consistência}

A criação de uma interface consistente, a qual usuário consiga rapidamente entender como funciona e possa confiar é de fundamental importância no mercado de aplicativos para smartphones. Isso pode ser feito a partir da definição e manutenção das expectativas dos usuários a partir dos elementos com os quais as pessoas já estão acostumadas, ou seja, estabelecer a consistência de interface. Estas expectativas são definidas pelo que as pessoas viram na tela durante a interação com o produto digital, assim como pelo que elas viram em interações com outras interfaces. Quando as ferramentas de usabilidade visual (layout, tipografia, cor, imagens, tratamentos, controles e funcionalidades) são utilizadas de forma consistente dentro de um aplicativo e seus widgets, pode-se dizer que a consistência foi alcançada.

\subsubsection{Hierarquia}

Hierarquia visual é a percepção e interpretação da importância relativa dos objetos, que no design de aplicativos são os elementos apresentados na tela. As diferenças visuais criadas através da localização, dos espaçamentos, das cores, dos tamanhos e os mais diversos tratamentos dos elementos de uma interface, são o meio pelo qual a hierarquia será atingida.

\subsubsection{Personalidade}

A aparência e o comportamento de uma interface causam impressões nos usuários que Schlatter e Levinson [2013] definem como a personalidade. Este eixo leva em consideração os aspectos visuais e como eles influenciam na forma como as pessoas usam e consideram um aplicativo. Layout, cor, $16^{\circ}$ Ergodesign - Congresso Internacional de Ergonomia e Usabilidade de Interfaces Humano Tecnológica: Produto, Informações Ambientes Construídos e Transporte

$16^{\circ}$ USIHC - Congresso Internacional de Ergonomia e Usabilidade de Interfaces Humano Computador

CINAHPA | 2017 - Congresso Internacional de Ambientes Hipermídia para Aprendizagem. tipografia, imagens, controles e funcionalidades, são os meios pelos quais se transmite a personalidade de um aplicativo, e pode-se dizer que o êxito foi obtido se esta percepção pelo usuário foi instantânea e ajuda a criar uma impressão positiva sobre o produto digital. Assim, se caracterizam dois tipos de impressão no nível visceral. A primeira, que é a approachability, está relacionada as qualidades estéticas clássicas, como organização, limpeza visual e simetria, e diz respeito ao quão útil um aplicativo parece ser. As qualidades estéticas expressivas, como a harmonia de design, harmonia das cores, dinamismo e expressão, são correspondentes a likability, a impressão de que algum aspecto da interface toca o usuário em nível pessoal ou ele simplesmente gosta do que vê.

\section{Análise}

A análise de similares é uma ferramenta de design com foco na estratégia, onde são identificados pontos negativos e positivos de aplicativos com propostas similares as do produto que será criado [PAZMINO, 2015]. Para isso, foram escolhidos três aplicativos, sendo um o líder na categoria (TripAdvisor) e os outros dois por se aproximarem do tema (Foodspotting e Foursquare).

\subsection{Trip Advisor}

Fundado em fevereiro de 2000, ativo em 48 países, o Trip Advisor é o maior site de viagens do mundo. Através do uso da ferramenta MATcH o aplicativo Trip Advisor. obteve 56.4 pontos, assim sendo, pode-se dizer que ele possui uma usabilidade alta. Isso se reflete na consistência do aplicativo, que é totalmente contemplada. Ao longo das telas são replicados os padrões de topo de página, margens, localização de botões e demais elementos que constituem o layout da interface como, por exemplo, a tipografia serifada escolhida. Apesar de a interface possuir uma paleta cromática definida e consistente, as cores dos ícones da tela inicial de busca são próximas. Pela possível confusão que esta semelhança pode causar, a consistência de cor é considerada parcial.

Dentre os outros elementos da interface, ainda podem ser analisadas as imagens do aplicativo e os
Realização:

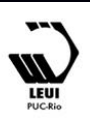




\section{$16^{\circ}$ \\ ERGODESIGN USIHC CINAHPA}

controles e funcionalidades. Existem duas formas de utilização de imagens no aplicativo analisado o que indicam uma consistência parcial. Isso porque nas fotos dos estabelecimentos e pontos turísticos apesar de as imagens serem sempre apresentadas de forma similar, com mesmo tamanho e localização, as fotos não são bastante variáveis. Já os ícones, são apresentados de forma consistente em todas as telas e ajudam na percepção dos controles e das funcionalidades. O tratamento dado aos elementos interativos do aplicativo é parcialmente consistente, pois não apresenta dicas visuais claras como o relevo ou o sombreamento de botões, mas apresenta ícones e está posicionado em locais que já são padrão para a plataforma onde o aplicativo está sendo utilizado.

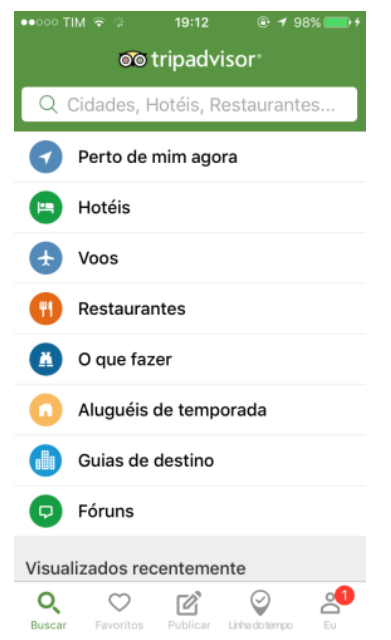

Imagem 1 -Tela inicial do Trip Advisor

Assim como na consistência, o layout, a tipografia, as cores e as imagens precisam ser utilizadas de forma que o usuário consiga perceber a hierarquia da interface. A maneira como a tipografia é trabalhada, com uma mesma fonte variando em tamanho e cor de acordo com o tipo de informação que ela apresenta é bastante eficiente para o objetivo do aplicativo. Por isso, pode-se dizer que o aplicativo de forma parcial o critério de hierarquia.

O TripAdvisor possui uma grande quantidade de funcionalidades e isso se reflete layout do aplicativo. Ainda que ele seja bem construído, são utilizados exclusivamente elementos clássicos, como elementos simples, formas retas e simetria.
Por sua paleta cromática muito limitada, o aplicativo não apresenta uma interface atraente. Dentro do objetivo ao qual o aplicativo se presta, ele atende sua proposta, mas ao considerar a personalidade, o ele atende apenas parcialmente este critério. Isso, porque além dos elementos anteriormente citados, suas imagens são pouco expressivas e seu sistema de iconografia também não traz contribuições relevantes para a interface.

\subsection{Foodspotting}

Com sua primeira versão lançada em 2010, o aplicativo Foodspotting é um guia visual da boa comida.

Tendo como base o uso do checklist MATcH, o aplicativo alcançou 47.1 pontos, o que significa que ele possui uma usabilidade razoável. Porém ao navegar pelas telas do aplicativo, percebe-se que a consistência de forma geral é fraca. Com uma paleta cromática de três cores usadas com pouco critério não há boa hierarquização da informação. Ainda que não haja uma grande variação de tamanhos e cores, a escolha tipográfica para a proposta do aplicativo hierarquiza a informação de forma eficiente, portanto a consistência tipográfica é total. De forma similar ao TripAdvisor, o Foodpotting também funciona de forma colaborativa, e por isso as imagens também são variáveis. Ainda assim, é possível afirmar que a consistência é parcial, pois os locais onde as imagens serão apresentadas foram previamente definidos no layout. Já os elementos interativos não apresentam nenhum tratamento especial. A única diferenciação é feita por meio da cor, mas alguns são tão diferenciados de seus semelhantes que parecem estar selecionados. O uso dos ícones não é intuitivo e isso pode ser percebido na página inicial os ícones que representam as palavras: amou, experimentou e quer. A quantidade de informações apresentadas por este aplicativo é substancialmente menor do que a do TripAdvisor. Ainda assim, pode-se dizer que o aplicativo atende apenas parcialmente o critério de hierarquia. Isso, porque apesar de ser respeitada uma certa hierarquização da informação, ela é muito fraca e os elementos não são explorados de maneira aprofundada.

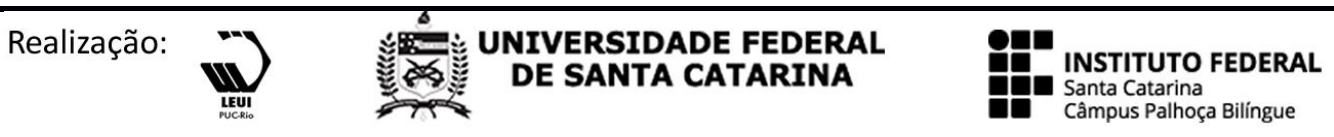




\section{$16^{\circ}$ \\ ERGODESIGN USIHC CINAHPA}

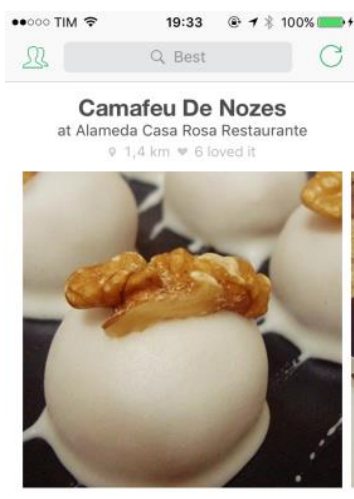

Q Near 2355 Rod. Amaro Antonio Vi... -

Imagem 2 - Tela inicial do Foodspotting

Dentre os aplicativos analisados, o Foodspotting é o que possui a proposta mais autêntica, mas a sua interface não atinge um bom grau de diferenciação. A mistura de elementos de estética clássica com apenas um elemento de grande expressividade, que é a fotografia da página inicial, não fortalece a diferenciação da interface. De forma geral, os elementos utilizados na interface, tanto as cores quanto os ícones e até mesmo as formas, parecem soltos e por isso pode-se afirmar que a interface não possui personalidade.

\subsection{Foursquare}

Ajudando a encontrar novos lugares através de recomendações confiáveis, o Foursquare faz parte da vida de cerca de 50 milhões de usuários desde $2009^{1}$. $\mathrm{O}$ aplicativo que conseguiu a maior nota na análise através da ferramenta $\mathrm{MATcH}$, de forma geral também contempla totalmente o critério de consistência de layout, pois os elementos utilizados são aplicados consistentemente ao longo das páginas. Não existe uma grande variação tipográfica, porque como os outros dois aplicativos ela utiliza apenas uma fonte, mas esta fonte é trabalhada cuidadosamente. Ao analisar as cores utilizadas na interface, pode-se afirmar que este critério também foi totalmente contemplado. Isso, porque a cor principal do aplicativo aparece consistentemente em

\footnotetext{
${ }^{1}$ https://foursquare.com/about acesso em: 15 set 2016
}

$16^{\circ}$ Ergodesign - Congresso Internacional de Ergonomia e Usabilidade de Interfaces Humano Tecnológica: Produto, Informações Ambientes Construídos e Transporte

$16^{\circ}$ USIHC - Congresso Internacional de Ergonomia e Usabilidade de Interfaces Humano Computador

CINAHPA | 2017 - Congresso Internacional de Ambientes Hipermídia para Aprendizagem.

todas as telas. Além disso, são utilizadas cores em pontos diferentes do layout que codificam diferentes pedaços de informação.

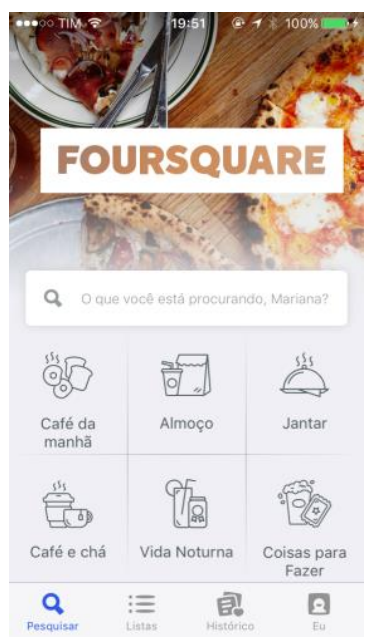

Imagem 3 - Tela inicial do Foursquare

Os aplicativos analisados possuem um ponto em comum, que é depender das imagens enviadas por seus usuários. Por isso o aplicativo acaba sendo apenas parcialmente consistente em suas imagens. Os elementos interativos do aplicativo são em sua maioria diferenciados dos demais elementos das telas e ao serem pressionados fornecem feedback ao usuário mudando de cor. A escolha e aplicação dos ícones na interface é adequada e quase todos são de fácil compreensão ou são rotulados. Quando se considera a hierarquia como um fator de análise, é possível afirmar que ela é totalmente contemplada. Elementos de mesma função são apresentados nos mesmos tamanhos, e dentro destes elementos quando necessário são aplicados recursos visuais que organizam eficientemente a informação. Percebe-se esmero no estabelecimento da personalidade da interface. Como dito anteriormente é definida uma cor principal, mas seu uso é apoiado por outras cores em pontos específicos, dentre elas podemos citar o verde, laranja, amarelo e rosa. Seus ícones possuem funções no decorrer da navegação e além disso são utilizados elementos expressivos no layout, como a reserva de espaços grandes para as imagens. Ainda que sejam respeitados e utilizados elementos da estética clássica, sua mescla com outros de maior expressividade faz com que o aplicativo seja atrativo, de fácil execução das tarefas. 


\section{$16^{\circ}$ \\ ERGODESIGN USIHC CINAHPA}

\section{Discussão}

\begin{tabular}{|c|c|c|c|}
\hline Critério & 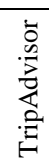 & $\begin{array}{l}00 \\
.0 \\
0 \\
0 \\
0 \\
0 \\
0 \\
0 \\
0\end{array}$ & 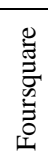 \\
\hline Consistência -Layout & & & \\
\hline Consistência Tipografia & & & \\
\hline Consistência - Cor & & & \\
\hline Consistência - Imagens & & & \\
\hline Consistência Controles e Affordances & & & \\
\hline Hierarquia & & & \\
\hline Personalidade & & & \\
\hline
\end{tabular}

\begin{tabular}{|l|l|}
\hline \multicolumn{2}{|c|}{ Legenda } \\
\hline Atende Totalmente & \\
\hline Atende Parcialmente & \\
\hline Não Atendende & \\
\hline
\end{tabular}

Quadro 1 - Resultados da análise de usabilidade visual

Com a ferramenta MATcH, o aplicativo que conseguiu a melhor pontuação foi o Foursquare, resultado semelhante ao conseguido a partir dos critérios estabelecidos por Schlatter e Levinson [2013], como pode ser observado no quadro 1. Ainda que seja baseada em critérios objetivos, esta análise é aplicada com subjetividade. Assim, os critérios ficam interligados e se o aplicativo analisado for bem em um critério, é provável que se saia bem nos outros também. Isso pode ser observado com o Foursquare, que além de atender totalmente os critérios em os demais, se sobressaiu no uso consistente das cores. E por isso, a percepção da sua personalidade é mais forte que a dos demais aplicativos analisados.

\section{Conclusão}

Por fim, pode-se dizer que a ferramenta MATcH guia muito bem aos pontos principais a serem observados em uma análise heurística. Mesmo que não contemple todas as possíveis respostas, $o$ MATcH é um checklist completo e um ponto de partida de fundamental importância para este tipo de análise. Para maior detalhamento, o registro de um pequeno relato é o suficiente para esta ferramenta já consolidada. Neste ponto a análise de $16^{\circ}$ Ergodesign - Congresso Internacional de Ergonomia e Usabilidade de Interfaces Humano Tecnológica: Produto, Informações Ambientes Construídos e Transporte

$16^{\circ}$ USIHC - Congresso Internacional de Ergonomia e Usabilidade de Interfaces Humano Computador

CINAHPA | 2017 - Congresso Internacional de Ambientes Hipermídia para Aprendizagem. usabilidade visual tem muito a contribuir, pois ela é feita de forma subjetiva observando e registrando com maior cuidado determinados aspectos da interface. Desta forma, a combinação entre a ferramenta MATcH e a análise de usabilidade visual vem como uma solução para o aproveitamento das potencialidades de ambas as análises para o levantamento de mais informações e a consequente obtenção de resultados aprofundados da análise de similares.

\section{BIBLIOGRAFIA}

BONSIEPE, Gui. Do material ao digital. São Paulo: Blucher, 2015. 234 p.

FEIJÓ, Valéria Casaroto. Heurística para Avaliação de Usabilidade em Interfaces de Aplicativos Smartphones: Utilidade, Produtividade e Imersão. Disponível em: <http://www.pgdesign.ufrgs.br/designetecnologia/in dex.php/det/article/view/141/85> Acesso em: 29 Ago. 2016.

NIELSEN, Jakob. 10 Usability Heuristics. Jakob Nielsen's Alertbox: January 1, 1995. Disponível em: <http://www.nngroup.com/articles/tenusability-heuristics/>. Acesso em: 19 fev. 2017.

PAZMINO, Ana Veronica. Como se cria: 40 métodos para design de produto. São Paulo: Blucher, 2015.

ROYO, Javier. Design Digital. São Paulo: Rosari, 2008. 169 p. (Fundamentos do Design).

SANTOS, Jucylene Araujo dos; SANTOS, Glauber Eduardo de Oliveira. Uso de smartphones em viagens de turismo: análise do comportamento do mercado paulistano. Turismo e Sociedade, [S.1.], v. 7, n. 4, out. 2014. ISSN 1983-5442. Disponível em: <http://revistas.ufpr.br/turismo/article/view/36323/2 5651>. Acesso em: 18 ago. 2016.

SCHLATTER, Tania; LEVINSON, Deborah. Visual Usability: Principles and Practices for Designing Digital Applications. Waltham: Morgan Kaufmann, 2013.
Realização:
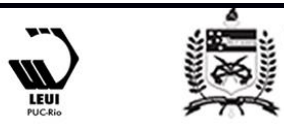


\section{$16^{\circ}$ \\ ERGODESIGN USIHC CINAHPA}

$16^{\circ}$ Ergodesign - Congresso Internacional de Ergonomia e Usabilidade de Interfaces Humano Tecnológica: Produto, Informações Ambientes Construídos e Transporte

$16^{\circ}$ USIHC - Congresso Internacional de Ergonomia e Usabilidade de Interfaces Humano Computador

CINAHPA | 2017 - Congresso Internacional de Ambientes Hipermídia para Aprendizagem.

UNGER, Russ; CHANDLER, Carolyn. O guia para projetar ux. Rio de Janeiro: Alta Books, 2009.

URRY, John. O Olhar do Turista: Lazer e viagens nas sociedades contemporâneas. São Paulo: Studo Nobel, 2001. 